Review

\title{
One-year survival after in-hospital cardiac arrest: A systematic review and meta-analysis
}

\author{
Marc Schluep $^{\mathrm{a}, *}$, Benjamin Yaël Gravesteijn ${ }^{\mathrm{a}}$, Robert Jan Stolker ${ }^{\mathrm{a}}$, Henrik Endeman ${ }^{\mathrm{b}}$, \\ Sanne Elisabeth Hoeks ${ }^{\mathrm{a}}$ \\ ${ }^{a}$ Department of Anaesthesiology, Erasmus University Medical Centre, Rotterdam, the Netherlands \\ ${ }^{\mathrm{b}}$ Department of Intensive Care Medicine, Erasmus University Medical Centre, Rotterdam, the Netherlands
}

\section{A R T I C L E I N F O}

\section{Keywords:}

In-hospital cardiac arrest

IHCA

Cardiac arrest

Survival

Long-term outcome

Systematic review

Meta-analysis

\begin{abstract}
A B S T R A C T
Introduction: In-hospital cardiac arrest is a major adverse event with an incidence of 1-6/1000 admissions. It has been poorly researched and data on survival is limited. The outcome of interest in IHCA research is predominantly survival to discharge, however recent guidelines warrant for more long-term outcomes. In this systematic review we sought to quantitatively summarize one-year survival after in-hospital cardiac arrest. Methods: For this systematic review and meta-analysis we performed a systematic search of all published data on one-year survival after IHCA up to March 9th, 2018. Results of the meta-analyses are presented as pooled proportions with corresponding 95\% prediction intervals (95\%PI). Between-study heterogeneity was assessed using $\mathrm{I}^{2}$ statistic and the DerSimonian-Laird estimator for $\tau^{2}$. Subgroup analyses were performed for cardiac and non-cardiac patients.

Results: We included 40 studies in our systematic review and meta-analysis. The pooled one-year survival after in-hospital cardiac arrest was $13.4 \%$ (95\%PI: 5.6-28.8\%, $\left.\mathrm{I}^{2}=100 \%\right)$. Subgroup analysis of cardiac patients revealed a one-year survival of $39.3 \%(16.1 \%-68.6 \%)$ in patients with a non-cardiac admission characteristic one-year survival was $10.7 \%(4.4 \%-23.6 \%)$. These data cover the period $1985-2018$ and show a modest change in survival over that period (10-year OR: 1.70, 95\% CI: 1.04-2.76).

Discussion: One-year survival after in-hospital cardiac arrest is poor. Survival is higher in patients admitted to cardiac wards. The time trend between 1985-2018 has shown a modest improvement in one-year survival rates. Research into IHCA population characteristics might elicit the issue of heterogeneity and stagnated survival over the past decades.
\end{abstract}

\section{Introduction}

Cardiac arrest, cardiopulmonary arrest, or circulatory arrest is the loss of mechanical heart function and effective blood circulation. If not treated by cardiopulmonary resuscitation (CPR) it inevitably means the end of life. However, if treated, circulation can be restored. Cardiac arrest is usually divided into two categories: out-of-hospital cardiac arrest (OHCA) and in-hospital cardiac arrest (IHCA). The latter is poorly researched; data on incidence and survival of IHCA are limited. Current literature describes an incidence of 1-6 events per 1000 hospital admissions [1-4].

The outcome of interest in IHCA research is predominantly survival to discharge. A recent meta-analysis shows a pooled survival rate at discharge of $15.0 \%$ (95\% CI, $12.0-18.0 \%$ ) with little change over time [5], while an analysis in the UK over the same period of time shows a significant increase in hospital survival after IHCA $(9.0 \%$ in 2004 to $12.2 \%$ in 2014) [6]. Survival to discharge is an important outcome measure, however little is known about the long-term outcomes of patients discharged from the hospital. Recent guidelines warrant for more research into long-term outcomes and associated factors [7]. As patient-centred outcomes are increasingly important to biomedical and clinical research, long-term survival could be regarded as such and could serve as important information in clinical decision-making. This systematic review aims to quantitatively summarize one-year survival after in-hospital cardiac arrest.

\footnotetext{
* Corresponding author at: Department of Anaesthesiology, Erasmus University Medical Centre, P.O. Box 2040, 3000CA, Rotterdam, the Netherlands.

E-mail address: m.schluep@erasmusmc.nl (M. Schluep).
} 


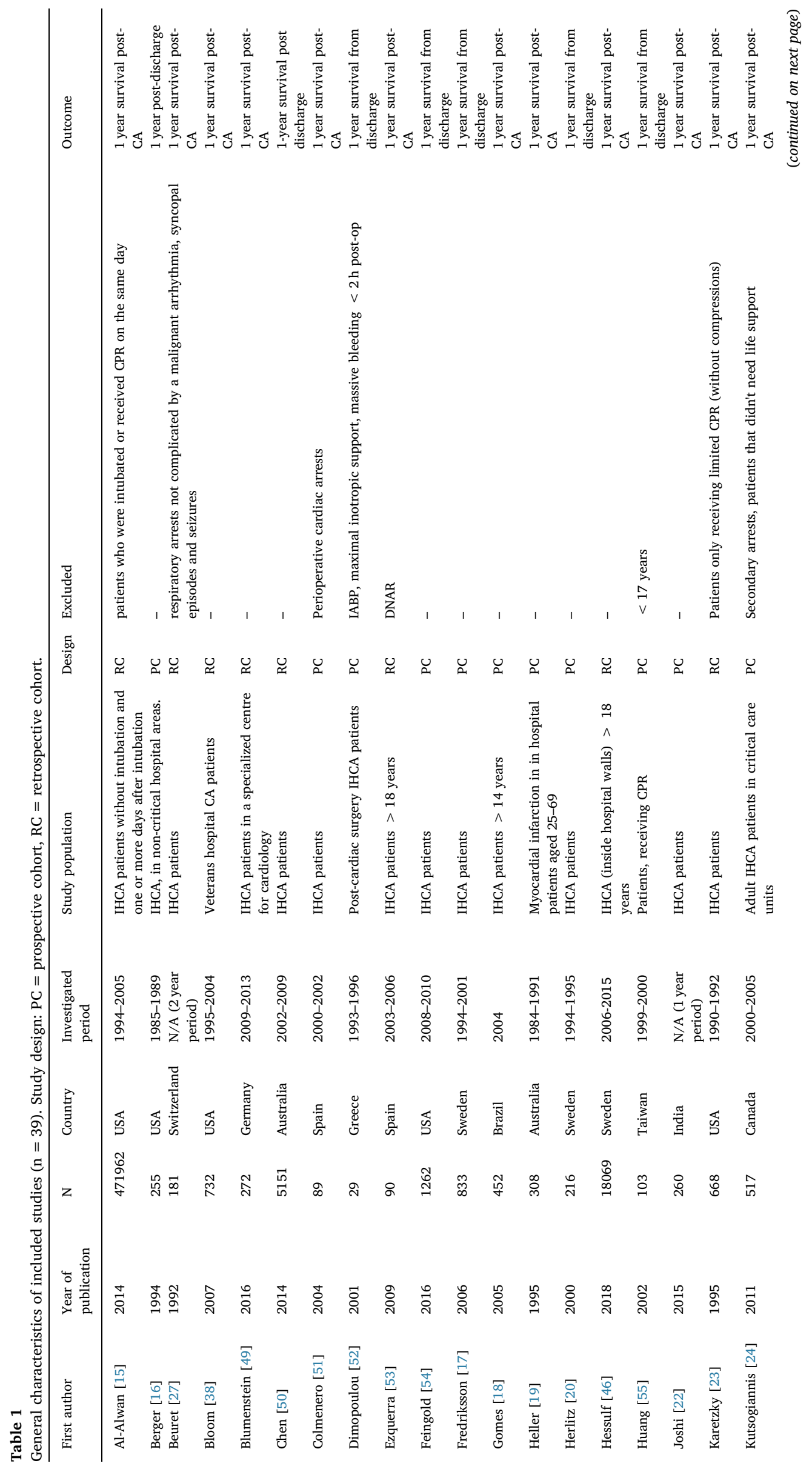




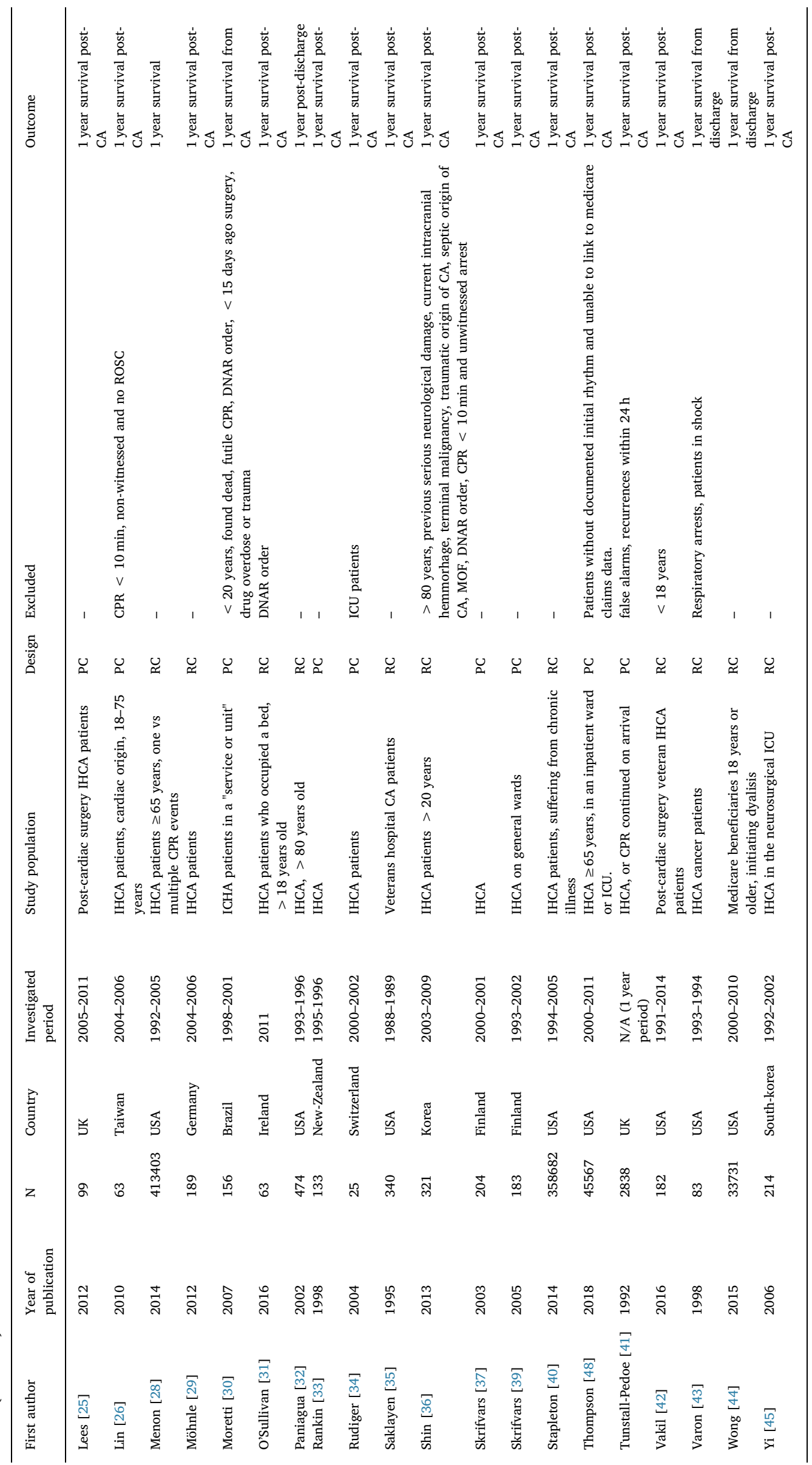


Methods

Search strategy and study selection

This systematic review and meta-analysis was reported following the PRISMA and MOOSE guidelines for reporting of systematic reviews and meta-analyses of observational studies [8,9]. The protocol was registered with PROSPERO (2017:CRD42017072037). We performed a systematic search of published data on one-year survival of IHCA using Embase, Medline Ovid, Cochrane Central, Web of Science, PubMed recent and Google scholar from their inception through March $9^{\text {th }}$, 2018. The search strategy is shown in supplemental Table 1 . We set no limitations on type of study or language. Mendeley (2017 Mendeley Ltd.) was used for the selection of relevant articles. Study selection was performed in a 2-staged process. Two reviewers (MS and BG) independently screened titles and abstracts (stage 1), and full-text papers for inclusion (stage 2). Disagreements were resolved with discussion and involvement of a third researcher (SH). Pre-defined inclusion criteria were: 1) In-hospital cardiac arrest, using conventional CPR (CCPR); 2) One year survival reported; 3) Adult patients; 4) Clinical study. Cardiac arrest definitions per article are provided in supplemental Table 2. Conventional CPR is defined as chest compressions with or without use of compression devices, as opposed to extracorporeal CPR via cardiopulmonary bypass. Studies were excluded if they did not fit inclusion criteria, if they were only published as abstract or written in a language none of the reviewers was proficient in.
Data extraction and quality assessment

Data extraction from selected studies was performed independently by two investigators (MS and BG) using a standardized form. To describe study design, we extracted the sample size of patients who underwent CCPR, the country of origin, the investigated period, the definition of the study population, whether the study was retrospective or prospective, how the investigators attained their data, which comparisons were made, how they defined one year survival and which patients were excluded from the cohort. Patient populations were checked for overlap to prevent patients from appearing multiple times in our analysis. If this was the case the study with the smallest sample size was excluded. The characteristics of the study population included were: age, gender, prevalence of cardiac patients, percentage of witnessed arrests or monitored patients and prevalence of ventricle fibrillation or ventricle tachycardia as initial rhythm. A common denominator for comorbidity or severity of disease was sought. If age was defined in strata or ranges a weighed mean was calculated without SD. Finally, one-year survival of patients who underwent CCPR in hospital was extracted. Survival was defined as the survival of one single CPR attempt. Authors were contacted for the exact survival rate when the oneyear survival was not directly available from the manuscript. We specifically looked at conventional CPR, and excluded extracorporeal CPR. When a study included both, only the conventional CPR group was extracted.

The quality of the studies was evaluated using the method of

Table 2

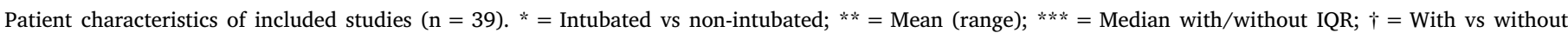
cardiac life support training groups (the survival is the overall survival).

\begin{tabular}{|c|c|c|c|c|c|c|}
\hline First author & Mean age ( \pm SD) & $\%$ male & $\%$ cardiac patients & $\%$ monitored/witnessed & $\% \mathrm{VF} / \mathrm{VT}$ & $\begin{array}{l}\% \text { CPC } 1 \text { or } 2 \\
\text { at } 1 \text { year }\end{array}$ \\
\hline Al-Alwan* [15] & $73.3( \pm 11.9)$ vs $75.0( \pm 11.4)$ & 50.4 vs 50.4 & N/A & $\mathrm{N} / \mathrm{A}$ & N/A & N/A \\
\hline Berger [16] & 67.4 & $\mathrm{~N} / \mathrm{A}$ & N/A & $\mathrm{N} / \mathrm{A}$ & 25.0 & $\mathrm{~N} / \mathrm{A}$ \\
\hline Beuret [27] & $61.5(17.0-89.0)^{* *}$ & 69.0 & $\mathrm{~N} / \mathrm{A}$ & 34.0 & 39.0 & N/A \\
\hline Bloom [38] & 59.0 & $\mathrm{~N} / \mathrm{A}$ & N/A & $\mathrm{N} / \mathrm{A}$ & $\mathrm{N} / \mathrm{A}$ & N/A \\
\hline Blumenstein [49] & $75.3(67.4-79.1)^{* * *}$ & 61.4 & 100 & 100 & 2.9 & $\mathrm{~N} / \mathrm{A}$ \\
\hline Chen [50] & $68.2( \pm 16.9)$ & 61.2 & N/A & $\mathrm{N} / \mathrm{A}$ & N/A & N/A \\
\hline Colmenero [51] & $68.0(56-74.5)^{* *}$ & 57.3 & $\mathrm{~N} / \mathrm{A}$ & $\mathrm{N} / \mathrm{A}$ & 34.8 & 100 \\
\hline Dimopoulou [52] & $61.0( \pm 11.0)$ & 87.5 & 100 & $\mathrm{~N} / \mathrm{A}$ & 44.0 & $\mathrm{~N} / \mathrm{A}$ \\
\hline Ezquerra [53] & $73.1( \pm 12.3)$ & 68.9 & N/A & $\mathrm{N} / \mathrm{A}$ & 22.2 & 93.0 \\
\hline Feingold [54] & $61.1( \pm 14.3)$ & 50.8 & N/A & $\mathrm{N} / \mathrm{A}$ & N/A & $\mathrm{N} / \mathrm{A}$ \\
\hline Fredriksson [17] & 69.4 & 63.0 & 66.0 & $\mathrm{~N} / \mathrm{A}$ & 48.6 & $\mathrm{~N} / \mathrm{A}$ \\
\hline Gomes [18] & 54.1 & 54.9 & $\mathrm{~N} / \mathrm{A}$ & 76.8 & 39.0 & N/A \\
\hline Heller [19] & 60.4 & 63.0 & N/A & $\mathrm{N} / \mathrm{A}$ & $\mathrm{N} / \mathrm{A}$ & $\mathrm{N} / \mathrm{A}$ \\
\hline Herlitz [20] & $68.0 * * *$ & 62.0 & N/A & $\mathrm{N} / \mathrm{A}$ & N/A & 95.0 \\
\hline Hessulf [46] & $75^{* * *}$ & 71.0 & 29.0 & 50.0 & 32.0 & $\mathrm{~N} / \mathrm{A}$ \\
\hline Huang [55] & 66.8 & 71.0 & 17.0 & $\mathrm{~N} / \mathrm{A}$ & 14.0 & $\mathrm{~N} / \mathrm{A}$ \\
\hline Joshi [22] & N/A & N/A & 31.2 & 91.0 & 21.9 & 96.0 \\
\hline Karetzky [23] & 59.2 & 48.2 & N/A & 65.7 & 15.7 & $\mathrm{~N} / \mathrm{A}$ \\
\hline Kutsogiannis [24] & $66.5( \pm 14.9)$ & 62.3 & 60.6 & 100 & 33.7 & $\mathrm{~N} / \mathrm{A}$ \\
\hline Lees [25] & N/A & N/A & 100 & 100 & 26.8 & $\mathrm{~N} / \mathrm{A}$ \\
\hline Lin [26] & $60.6( \pm 12.7)$ & 65.1 & 47.6 & $\mathrm{~N} / \mathrm{A}$ & 41.3 & 91.0 \\
\hline Menon [28] & 78.3 vs. 77.4 & 50.5 vs 50.7 & N/A & $\mathrm{N} / \mathrm{A}$ & $\mathrm{N} / \mathrm{A}$ & $\mathrm{N} / \mathrm{A}$ \\
\hline Möhnle [29] & $65.2( \pm 16.1)$ & 69.8 & N/A & 21.7 & 32.3 & $\mathrm{~N} / \mathrm{A}$ \\
\hline Moretti ${ }^{\dagger}[30]$ & $64.4( \pm 17.2)$ vs $63.6( \pm 15.8)$ & 58.6 vs 55.2 & N/A & 90.3 vs 74.6 & 32.7 vs 22.1 & $\mathrm{~N} / \mathrm{A}$ \\
\hline O'Sullivan [31] & $74.3^{* * *}$ & 63.4 & 44.4 & 87.3 & 30.2 & 81.0 \\
\hline Paniagua Paniagua [32] & $86.0( \pm 4.8)$ & 42.0 & $\mathrm{~N} / \mathrm{A}$ & $\mathrm{N} / \mathrm{A}$ & $\mathrm{N} / \mathrm{A}$ & $\mathrm{N} / \mathrm{A}$ \\
\hline Rankin [33] & N/A & $\mathrm{N} / \mathrm{A}$ & $\mathrm{N} / \mathrm{A}$ & 47.4 & 32.3 & 100 \\
\hline Rudiger [34] & 72.8 & 72.0 & N/A & $\mathrm{N} / \mathrm{A}$ & 28.0 & N/A \\
\hline Saklayen [35] & 66.9 & $\mathrm{~N} / \mathrm{A}$ & N/A & 57.0 & 18.0 & $\mathrm{~N} / \mathrm{A}$ \\
\hline Shin [36] & $61.6( \pm 14.2)$ & 62.6 & 49.5 & 100 & 22.7 & N/A \\
\hline Skrifvars [37] & $68.0( \pm 15.8)$ & 59.3 & $\mathrm{~N} / \mathrm{A}$ & 72.1 & 28.0 & N/A \\
\hline Skrifvars [39] & $73(64.0-78.0)^{* * *}$ & 60.0 & $\mathrm{~N} / \mathrm{A}$ & 75.4 & 33.3 & $\mathrm{~N} / \mathrm{A}$ \\
\hline Stapleton [40] & $78.9( \pm 7.2)$ & 50.3 & N/A & $\mathrm{N} / \mathrm{A}$ & N/A & N/A \\
\hline Thompson [48] & $77.2( \pm 7.4)$ & 55.5 & 26.7 & 25.3 & 20.3 & N/A \\
\hline Tunstall-Pedoe [41] & N/A & 64.2 & N/A & $\mathrm{N} / \mathrm{A}$ & N/A & N/A \\
\hline Vakil [42] & $68.0( \pm 8.0)$ & 98.0 & 100 & $\mathrm{~N} / \mathrm{A}$ & 71.4 & $\mathrm{~N} / \mathrm{A}$ \\
\hline Varon [43] & 56.2 & 49.3 & N/A & $\mathrm{N} / \mathrm{A}$ & N/A & N/A \\
\hline Wong [44] & $>65.0$ & 53.9 & 16.7 & N/A & N/A & N/A \\
\hline Yi [45] & $54.0( \pm 9.4)$ & 65.5 & 19.2 & 100 & 29.0 & $\mathrm{~N} / \mathrm{A}$ \\
\hline
\end{tabular}




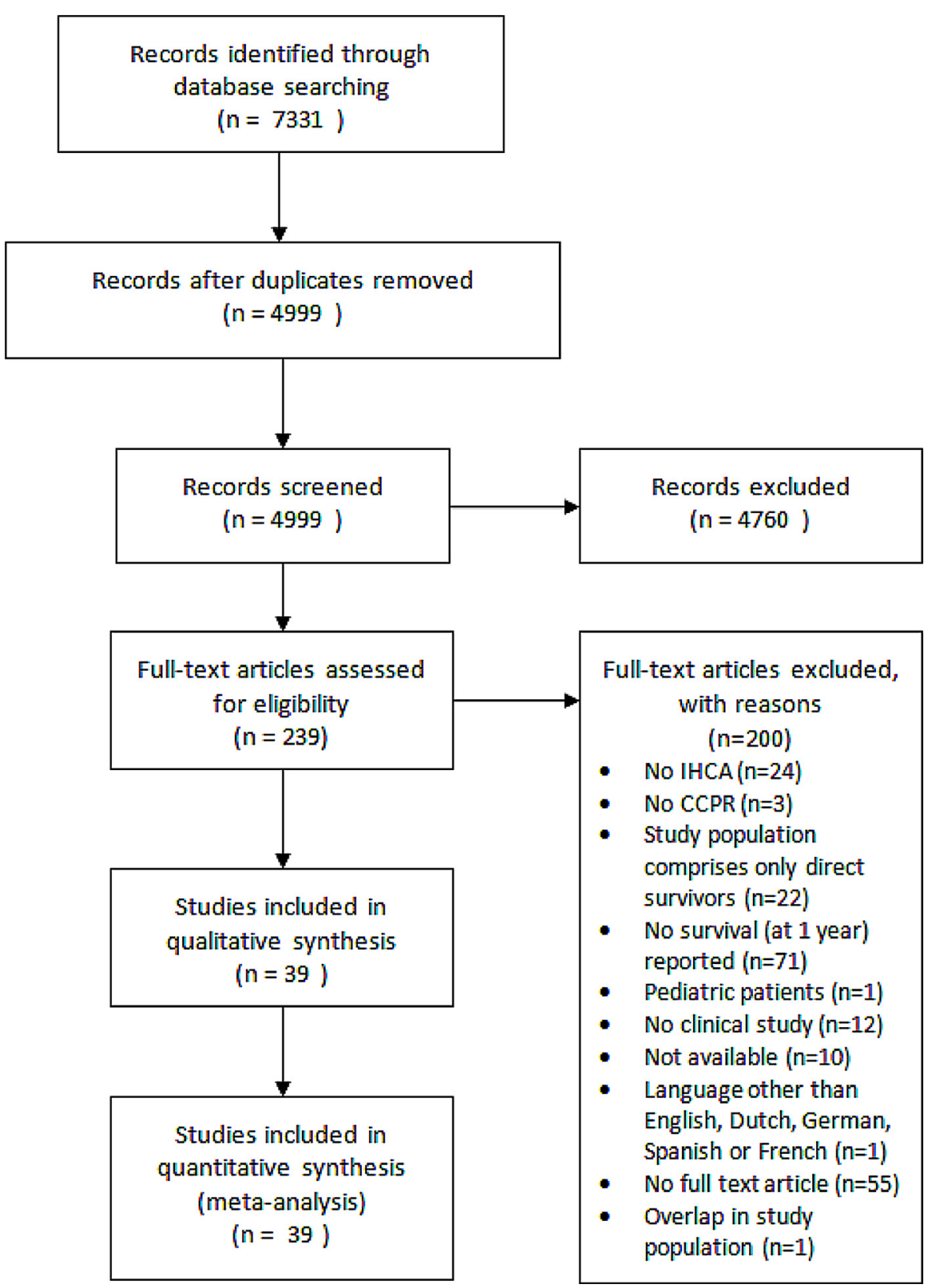

Fig. 1. PRISMA Flow Diagram of search strategy and included studies.

Table 3

Summary of outcomes from the performed meta-analyses. All survival rates are presented with a $95 \%$ prediction interval (95\%PI). Non-cardiac was defined as studies not included in the cardiac subgroup analysis.

\begin{tabular}{|c|c|c|c|c|}
\hline $\begin{array}{l}\text { Survival rates } \\
(\%, 95 \% \mathrm{PI})\end{array}$ & $\begin{array}{l}\text { Survival to } \\
\text { discharge }\end{array}$ & $\begin{array}{l}\mathrm{I}^{2}, \tau^{2} \\
\mathrm{p} \text {-value }\end{array}$ & $\begin{array}{l}\text { One-year } \\
\text { survival }\end{array}$ & $\begin{array}{l}\mathrm{I}^{2}, \tau^{2}, \\
\text { p-value }\end{array}$ \\
\hline Overall & $\begin{array}{l}17.6 \\
(13.1-22.7)\end{array}$ & $\begin{array}{l}99 \%, 0.03 \\
<0.01\end{array}$ & $13.4(5.6-28.8)$ & $\begin{array}{l}100 \%, 0.22 \\
<0.01\end{array}$ \\
\hline Cardiac & $49.7(3.8-96.2)$ & $\begin{array}{l}88 \%, 0.44 \\
<0.01\end{array}$ & $\begin{array}{l}39.3 \\
(16.1-68.6)\end{array}$ & $\begin{array}{l}85.0 \%, 0.16 \\
<0.01\end{array}$ \\
\hline Non-cardiac & $\begin{array}{l}15.9 \\
(12.0-20.7)\end{array}$ & $\begin{array}{l}99 \%, 0.02 \\
<0.01\end{array}$ & $\begin{array}{l}10.7(4.4- \\
23.6)\end{array}$ & $\begin{array}{l}100 \%, 0.21 \\
<0.01\end{array}$ \\
\hline
\end{tabular}

Hayden et al. for the evaluation of the quality of prognosis studies in systematic reviews [10]. Known prognostic factors such as initial rhythm and witnessed arrest were assessed. Two authors individually assessed all six items and discrepancies were resolved by a third researcher (SH).
Statistical analysis

One-year survival data were pooled across studies using the inverse variance method. A random-effects model was used to estimate the pooled one-year survival probability after IHCA as considerable heterogeneity was expected. A random-effects meta-analysis model assumes the observed estimates can vary across studies because of real differences in each study as well as sampling variability (chance). Results of the meta-analyses are presented as pooled proportions with corresponding 95\% confidence intervals (CI). Between-study heterogeneity was assessed using $I^{2}$ statistic and the DerSimonian-Laird estimator for $\tau^{2}$. Furthermore in order to address heterogeneity between studies better, a 95\% prediction interval was reported [11,12].

A sensitivity analysis was performed to assess the presence or absence of heterogeneity. Subgroup analyses were performed for cardiac and other patients. Cardiac, or a cardiac admission characteristic, was defined as a study in which all patients came from cardio (-thoracic) units, or were predominantly admitted to the hospital for cardiac 


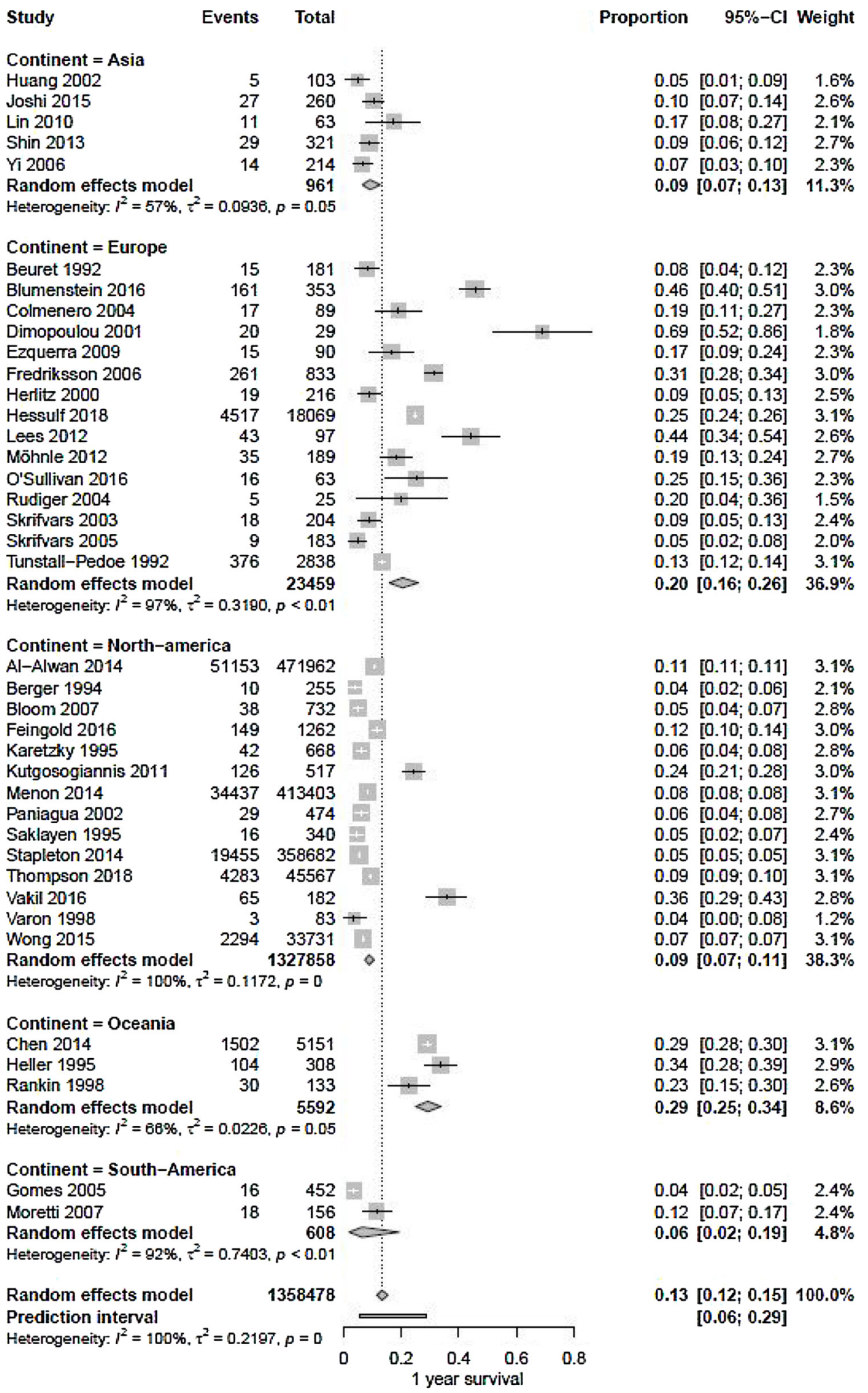

Fig. 2. Pooled one-year survival rate after in-hospital cardiac arrest.

disease or cardiac surgery. The non-cardiac subgroup consisted of studies that included patients who were not specifically admitted for cardiologic or cardiac surgical reasons (i.e. general nursing wards, but also critical care units). Other subgroup analyses were done for study quality, geographical distribution (i.e. continents) and initial arrest rhythm. Furthermore, a random intercept meta-regression analysis (binomial-normal model) with corresponding bubble plot was carried out to assess the influence of study period on one-year survival. This model is appropriate for probability meta regression, since it avoids the bias that occur when a normal-normal model would be used for logit transformed proportion [13,14]. Studies were allocated in time using the median of the period the study covered. After careful evaluation of all articles a post-hoc analysis of cognitive outcome was done with use of a random effects model to analyse available data on the fraction of 


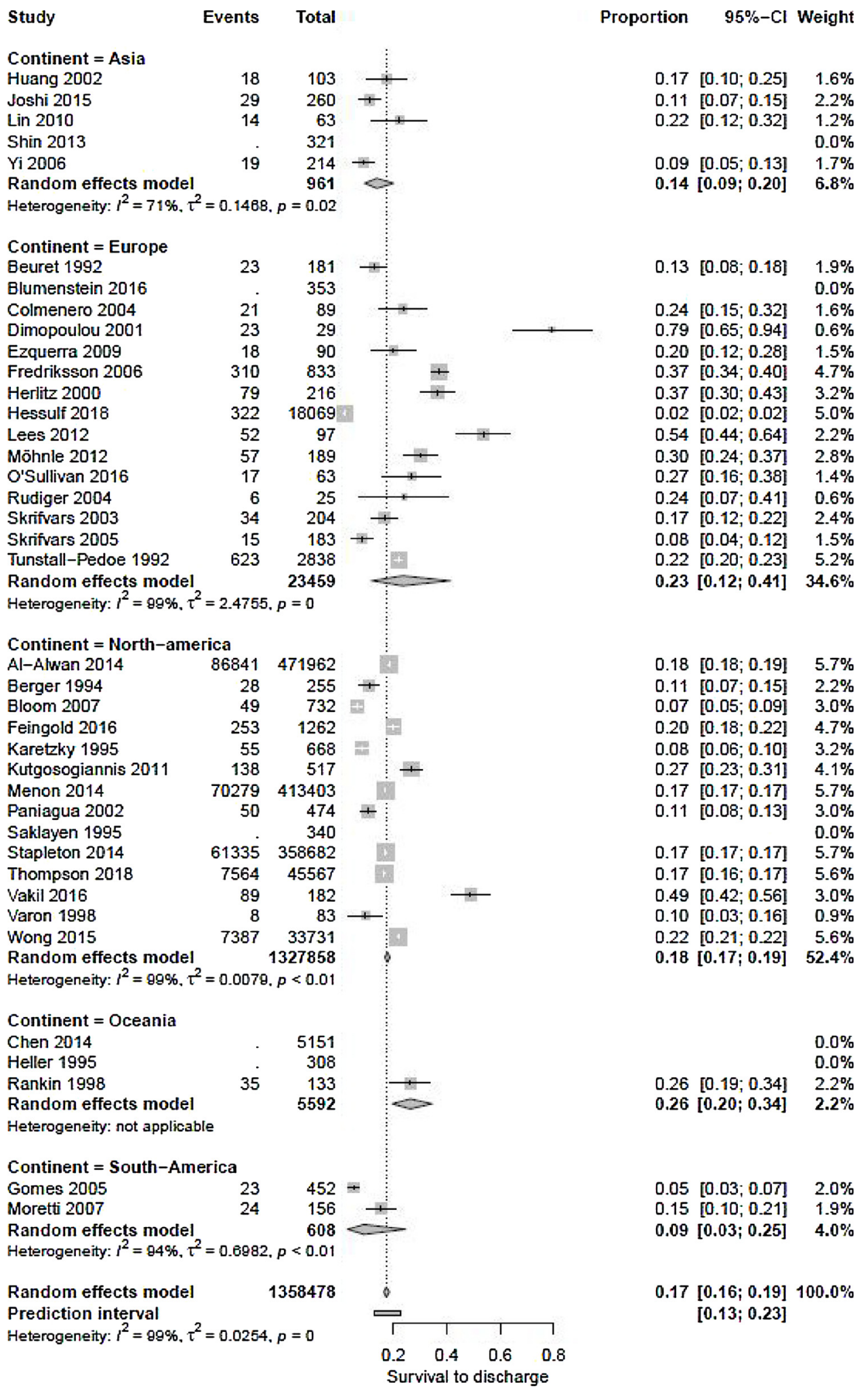

Fig. 3. Pooled survival to discharge rate after in-hospital cardiac arrest for studies that reported this outcome measure.

one-year survivors with a cerebral performance category score (CPC) of 1 or 2. Secondly a post-hoc analysis was performed for survival to discharge.

All data was extracted into Microsoft Excel and then statistically analysed by importing the data in R (R Core Team (2013). R: A language and environment for statistical computing. $\mathrm{R}$ Foundation for Statistical Computing, Vienna, Austria.). The packages used for the analysis were 'meta' and 'metafor', of which we used the 'metaprop', forrest' and 'rma.glmm functions. 


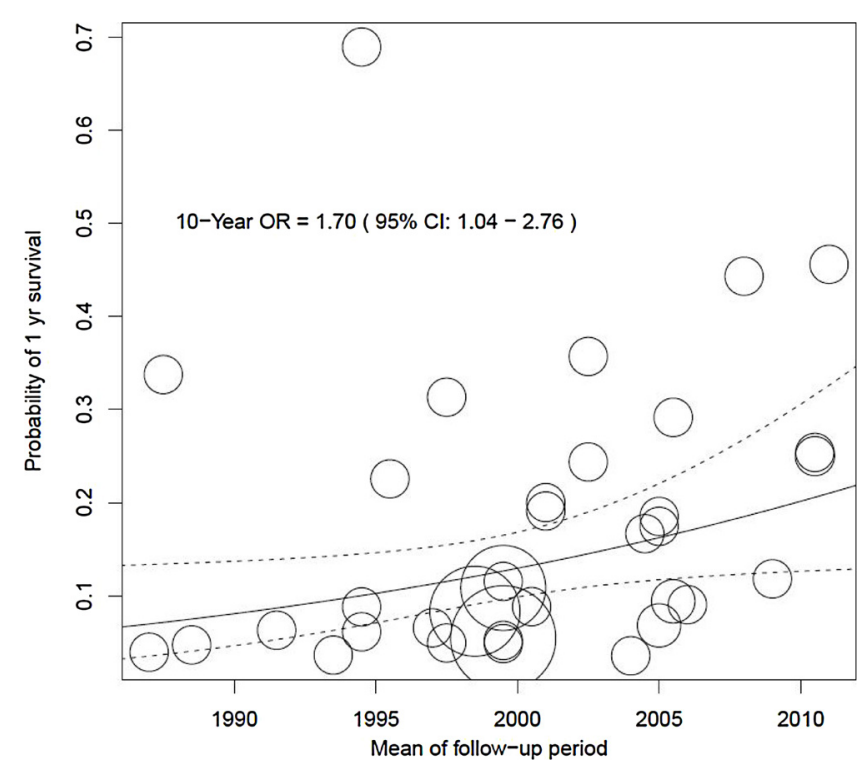

Fig. 4. Bubble-plot for meta-regression analysis of the influence of study period on one-year survival ( $\mathrm{OR}=1.70,95 \% \mathrm{CI}$ : $1.04-2.76$ per ten year increase).

\section{Results}

Search results and characteristics of included studies

Our search strategy retrieved 7331 records, of which 4999 remained after duplicates were removed. The parallel exclusion of studies based on title and abstract resulted in 239 full text articles eligible for detailed assessment. Finally, we included 39 studies in our systematic review and meta-analysis [15-54]. Full details of study selection are summarized in Fig. 1.

Characteristics of the included studies and study populations are given in Tables 1 and 2. All studies were performed between 1985 and 2015, predominantly in North America and Western Europe. Data was available on age in $35(89.7 \%)$ studies, on gender in $33(84.6 \%)$, on the proportion of cardiac patients in 14 (35.9\%) studies and on shockable rhythm in 27 (69.2\%) of the included studies. Of the included studies $18(46.1 \%)$ described level of patient monitoring at the time of arrest (e.g. critical care units). Number of inclusions ranged from 25 to 471,962 patients and mean age of the study population ranged from 54 to 86 years.

\section{Quality assessment}

The quality assessment of the included studies is given in supplemental Table 3 . The study population was adequately defined and described in $26(66.6 \%)$ studies. The study attrition, referring to the manner in which patients were recruited for inclusion, was of good quality in $28(71.8 \%)$ studies. Prognostic factors were adequately measured in $21(53.8 \%)$ studies. The means of outcome measurement were not or inadequately described in $16(41.0 \%)$ studies, and were sufficiently described and measured in $12(30.8 \%)$ studies.

\section{Outcome}

The meta-analysis of all studies showed a pooled one-year survival of $13.4 \%$ (95\%PI: 5.6\%-28.8\%) summarized in Fig. 2. Statistical heterogeneity was high: $\mathrm{I}^{2}=100 \%, \tau^{2}=0.22, \mathrm{p}<0.01$. Subgroup analysis of cardiac patients revealed a one-year survival of $39.3 \%$ (95\%PI: $16.1 \%-68.6 \% ; I^{2}=85.0 \%$ ), while repeating this analysis in studies of the non-cardiac subgroup analysis resulted in a one year survival of 10.7\% (95\% PI: 4.4\%-23.6\%; $I^{2}=100 \%$ ) Survival plots for cardiac and non-cardiac patients are available in supplemental Figs. 1 and 2. As displayed in Fig. 3 survival to discharge was available in 35 studies. Pooled survival to discharge was $17.6 \%$ (95\%PI: $13.1-22.7 \%$, $\left.I^{2}=99 \%\right)$. All survival statistics are summarized in Table 3.

Finally, when analysing the temporal trend of one year survival, a significant and modestly positive trend was observed ( $\mathrm{OR}=1.70$ per 10-year period, 95\%CI: 1.04-2.76), as shown in Fig. 4. Seven studies reported CPC scores for one-year survivors. A pooled estimate shows 92.0\% (95\% CI: 85.0\%-96\%) of patients alive at one year after cardiac arrest have a CPC score of 1 or 2 (Fig. 5). Pooled estimates stratified by study quality, geographical distribution or initial arrest rhythm did not produce any significant differences in effect estimates or heterogeneity. We were not able to identify a common denominator of comorbidity or severity of disease to perform analyses on.

\section{Discussion}

In this systematic review one-year survival after in-hospital cardiac arrest is $13.4 \%$ (95\%PI: $5.6 \%-28.8 \%$ ). When viewed separately oneyear survival in cardiac vs. non-cardiac patients is $39.3 \%$ and $10.7 \%$ respectively. As far as we have found these data represent the first documentation of a systematic overview on one-year survival after IHCA through most recent publications and covers the period 1985-2018.

One-year survival of $13.4 \%$ after IHCA is poor. When compared to survival to discharge this implies a large portion of patients discharged alive survive the following year $[5,6]$. The low survival rate is probably attributable to the presence of underlying disease. Comorbid disease has been demonstrated to worsen survival. This is most evident for severe COPD, cirrhotic liver disease, chronic kidney disease and heart failure and is supported by recent evidence that links comorbidity and age to 30-day survival [55]. Although we did not have sufficient data for a subgroup analysis, some of the studies we have included suggest a similar relationship between comorbidity and long-term survival $[40,55]$.

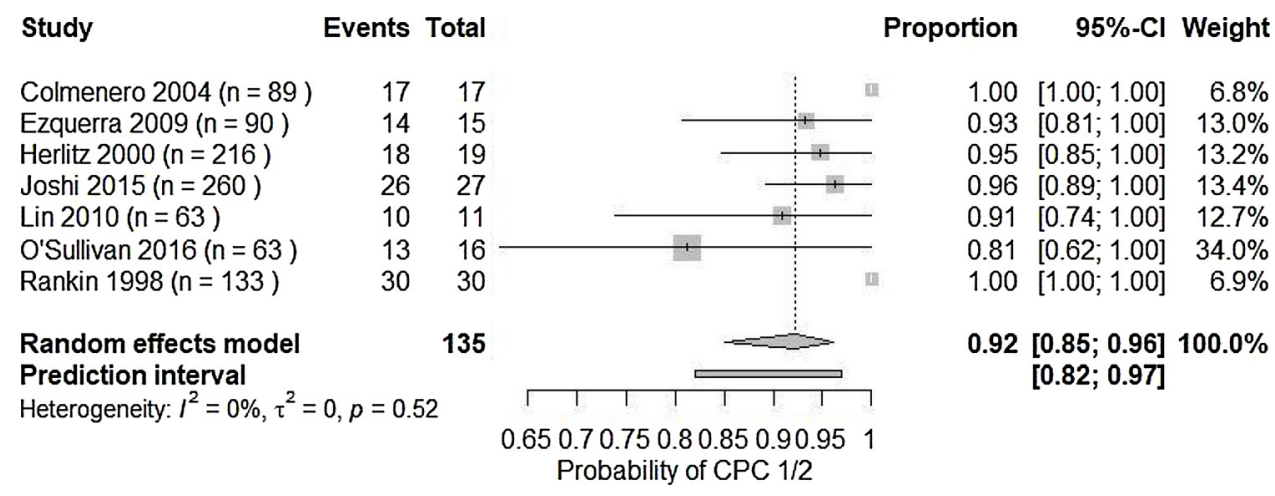

Fig. 5. Pooled fraction of survivors at 1 year with a cerebral performance category of 1 or 2 . 
We found significant heterogeneity in outcomes across the studies. These differences may be related to the variability in study populations, treatment strategies and/or international differences in life expectancy [56]. With regard to differences in study population, subgroup analyses showed a survival of $39.3 \%$ in patients who are admitted to hospital for cardiac disease or cardiac surgery. In these patients survival is higher than for patients admitted for other reasons and part of the heterogeneity can be explained by this subgroup analysis. The higher survival rates are related to the presence of monitored wards, a higher incidence of shockable rhythm (also demonstrated in this review) and presumably a higher incidence of reversible causes (e.g. tamponnade, coronary occlusion) [57]. This supports the hypothesis of earlier recognition and intervention, as well as higher baseline survival in cardiac patients compared to other patients after cardiac arrest. To further explain heterogeneity we have performed several subgroup analyses with the available information, but did not find any sufficient answer.

The heterogeneity of data can to greater extent be attributed to the epidemiological nature of the populations, rather than being selected or randomized groups. We believe that pooling of data was reasonable for outcome measures for different reasons. First (I) this approach is pragmatic and clinically relevant; (II) we took measures to reduce potential clinical heterogeneity by performing subgroup analyses on the basis of clinical criteria (i.e. cardiac vs. non-cardiac patients) (III) by contrast with comparative meta-analyses in which the presence of statistical heterogeneity might limit conclusions about effect size or exposure, pooling of data is an accepted method in single-group metaanalyses done for epidemiological purposes and (IV) pooling the data was necessary to appraise the available data on one-year survival in a comprehensive manner that could help inform the clinical context and related clinical decision making [58]. Although generalizability is limited due to a large diversity in study populations, pooling due of data provides a clinically relevant estimate for one-year survival after IHCA. In reporting survival rates we used the prediction interval, rather than the confidence interval. This provides an estimate of what survival rates can be expected in future studies. As to be expected with large heterogeneity in outcomes the prediction intervals we found were very broad and make prognostication difficult.

We compared one-year survival to survival to discharge from a recent meta-analysis (i.e. $15.0 \% 95 \%$ CI: $12.0 \%-18.0 \%$ ) and to survival to discharge from this meta-analysis (i.e. $17.6 \%$, 95\%CI $13.1 \%-22.7 \%$ ) [5]. It suggests death after IHCA occurs mainly during hospital admission rather than after discharge. Furthermore, when pooled survival for in-hospital cardiac arrest patients is compared to one-year survival after out-of-hospital cardiac arrest survival it is nearly identical: $13.4 \%$ for IHCA vs. $12.0 \%$ for OHCA [59,60]. These data give rise to new questions regarding the aetiology of IHCA in non-cardiac patients and factors that influence survival. It could be argued that factors concerning pre-existing health status have added value in predicting oneyear survival after in-hospital cardiac arrest. A positive finding came from our analysis for cognitive performance showed CPC scores were 1 or 2 in $92.0 \%$ (95\% CI: $85.0 \%-96.0 \%$ ) of one-year survivors. This however pertains to performance and not necessarily to quality of life.

Certain limitations should be taken into account. Most studies have reported one-year survival from the moment of cardiac arrest, with a few reporting survival from the moment of discharge. We have considered this difference to be negligible to the interpretation of our outcome because survival is measured at least one year from the occurrence of cardiac arrest. Secondly we need to consider the heterogeneity of outcomes, as population-level data was not available for many of the included studies and therefore only stratification for cardiac and non-cardiac patients rather than for comorbidity or age was possible. No difference could be analysed between monitored or nonmonitored wards or initial arrest rhythms, as sufficient data was not available. Although some subgroup analyses were attempted no clear explanation for this heterogeneity could be pinpointed. Lastly health care developments and changes in public health will have influenced incidence and outcome of IHCA. The meta-regression we have performed shows a trend in one-year survival that shows a slight improvement when viewed on a basis of 10-year intervals. One could state that survival improves over time, however this trend is only modestly positive and we hope this effect will become more evident in the future. Whether patient case mix has significantly altered, treatment strategies are insufficient or it is a combination of factors remains uncertain.

In the future heterogeneity in structure and processes of care should be explored. This variation in practice also adds to the heterogeneity in outcome. We do believe that careful assessment of quality of care should be performed, taking into account statistical uncertainty and case-mix. Being able to explain differences in outcome through quality of care could enable improving overall quality of care by identifying the most effective policy [61]. Secondly subgroup analyses can be performed if predefined subgroups are available. These subgroups need to be defined by known predictors and need to be comparable between studies [62]. We would recommend the implementation of nationwide registries and the use of standardized sets for reporting populations and outcomes, in this case the Utstein criteria and Core Outcome Set for Cardiac Arrest (COSCA) [63-65]. This will help improve comparability and enhance future implementation research [66].

This meta-analysis contains important information pertaining to all patients worldwide. In-hospital cardiac arrest is a global health issue, which concerns all patients and health care workers. Before making decisions about cardiopulmonary resuscitation and treatment restrictions, physicians must communicate accurate expectations of outcome to patients and families. However, one important caveat when reviewing these survival data is that its applicability to individual patients is limited. Although data on long-term outcome can inform patients on medical decisions about CPR, these data represent survival spread over a large population rather than predicting the trajectory for any individual patient. Overall we can conclude that one-year survival is poor in patients admitted to hospital for non-cardiac disease. Specific patient-level prognostication may probably require more knowledge about age, comorbidity and intercurrent disease.

In conclusion, our systematic review showed a one-year survival of $13.4 \%$ in IHCA patients. The time trend between 1985-2018 has shown a modest improvement in one-year survival rates. Future research is needed, specifically into the subject of prognostic factors for long-term qualitative outcome. Furthermore description of IHCA populations might elicit the issue of stagnated survival over the past decades. Moreover, more studies are published randomizing extracorporeal CPR vs. conventional CPR, which in the future could be a more common method of resuscitation [67]. We feel multicentre prospective research in a known source population is needed to improve current knowledge on this subject.

\section{Declaration of interest}

The authors state that there is no conflict of interest.

\section{Acknowledgements}

We would kindly like to thank Gerdien de Jonge from the Erasmus University Medical Centre library for her aid in our literature search and we would like to thank professor Matthias Egger for his help in analysing the temporal trend of survival.

\section{Appendix A. Supplementary data}

Supplementary material related to this article can be found, in the online version, at doi:https://doi.org/10.1016/j.resuscitation.2018.09. 001. 


\section{References}

[1] Skogvoll E, Isern E, Sangolt GK, Gisvold SE. In-hospital cardiopulmonary resuscitation: 5 years' incidence and survival according to the Utstein template. Acta Anaesthesiol Scand 1999;43:177-84.

[2] Hodgetts TJ, Kenward G, Vlackonikolis I, Payne S, Castle N, Crouch R, et al. Incidence, location and reasons for avoidable in-hospital cardiac arrest in a district general hospital. Resuscitation 2002;54:115-23.

[3] Sandroni C, Nolan J, Cavallaro F, Antonelli M. In-hospital cardiac arrest: incidence, prognosis and possible measures to improve survival. Intensive Care Med 2007;33:237-45.

[4] Fennessy G, Hilton A, Radford S, Bellomo R, Jones D. The epidemiology of inhospital cardiac arrests in Australia and New Zealand. Intern Med J 2016;46(10):1172-81.

[5] Zhu A, Zhang J. Meta-analysis of outcomes of the 2005 and 2010 cardiopulmonary resuscitation guidelines for adults with in-hospital cardiac arrest. Am J Emerg Med 2016;34:1133-9.

[6] Nolan JP, Ferrando P, Soar J, Benger J, Thomas M, Harrison DA, et al. Increasing survival after admission to UK critical care units following cardiopulmonary resuscitation. Crit Care 2016;20.

[7] Bossaert LL, Perkins GD, Askitopoulou H, Raffay VI, Greif R, Haywood KL, et al European Resuscitation Council Guidelines for Resuscitation 2015 Section 11. The ethics of resuscitation and end-of-life decisions on behalf of the ethics of resuscitation and end-of-life decisions section Collaborators 1. Resuscitation 2015;95:302-11.

[8] Moher D, Liberati A, Tetzlaff J, Altman DG, PRISMA Group. Preferred reporting items for systematic reviews and meta-analyses: the PRISMA statement. PLoS Med 2009; 6:e1000097.

[9] Stroup DF, Berlin JA, Morton SC, Olkin I, Williamson GD, Rennie D, et al. Metaanalysis of observational studies in epidemiology: a proposal for reporting. JAMA Am Med Assoc 2000;283. 2008.

[10] Hayden JA, Côté P, Bombardier C. Evaluation of the quality of prognosis studies in systematic reviews. Ann Intern Med 2006;144:427-37.

[11] IntHout J, Ioannidis JPA, Rovers MM, Goeman JJ. Plea for routinely presenting prediction intervals in meta-analysis. BMJ Open 2016;6:e010247.

[12] Borenstein M, Higgins JPT, Hedges LV, Rothstein HR. Basics of meta-analysis: $I^{2}$ is not an absolute measure of heterogeneity. Res Synth Methods 2017;8:5-18.

[13] Stijnen T, Hamza TH, Özdemir P. Random effects meta-analysis of event outcome in the framework of the generalized linear mixed model with applications in sparse data. Stat Med (Wiley-Blackwell) 2010;29:3046-67.

[14] Zürcher K, Mooser A, Anderegg N, Tymejczyk O, Couvillon MJ, Nash D, et al. Outcomes of HIV-positive patients lost to follow-up in African treatment programmes. Trop Med Int Health 2017;22:375-87.

[15] Al-Alwan A, Ehlenbach WJ, Menon PR, Young MP, Stapleton RD. Cardiopulmonary resuscitation among mechanically ventilated patients. Intensive Care Med 2014;40:556-63.

[16] Berger R, Kelley M. Survival after in-hospital cardiopulmonary arrest of non critically ill patients: a prospective study. Chest 1994;106:872-9.

[17] Fredriksson M, Aune S, Thoren AB, Herlitz J. In-hospital cardiac arrest—an Utstein style report of seven years experience from the Sahlgrenska University Hospital. Resuscitation 2006;68:351-8.

[18] Gomes AM, Timerman A, Souza CA, Mendes CM, Povoas Filho HP, Oliveira AM, et al. Prognostic factors of survival in post-cardiopulmonary-cerebral resuscitation in general hospital. Arq Bras Cardiol 2005;85:262-71.

[19] Heller RF, Steele PL, Fisher JD, Alexander HM, Dobson AJ. Success of cardiopulmonary resuscitation after heart attack in hospital and outside hospital. Br Med J 1995;311:1332-6.

[20] Herlitz J, Andreasson AC, Bang A, Aune S, Lindqvist J. Long-term prognosis among survivors after in-hospital cardiac arrest. Resuscitation 2000;45:167-71.

[21] Huang CH, Chen WJ, Ma MHM, Chang WT, Lai CL, Lee YT. Factors influencing the outcomes after in-hospital resuscitation in Taiwan. Resuscitation 2002;53:265-70.

[22] Joshi M. A prospective study to determine the circumstances, incidence and outcome of cardiopulmonary resuscitation in a referral hospital in India, in relation to various factors. Indian J Anaesth 2015;59:31-6.

[23] Karetzky M, Zubair M, Parikh J. Cardiopulmonary-resuscitation in intensive-care unit and non-intensive care unit patients-immediate and long-term survival. Arch Intern Med 1995;155:1277-80.

[24] Kutsogiannis DJ, Bagshaw SM, Laing B, Brindley PG. Predictors of survival after cardiac or respiratory arrest in critical care units. Can Med Assoc J 2011;183:1589-95.

[25] Lees NJ, Powell SJ, Mackay JH. Six-year prospective audit of "scoop and run" for chest-reopening after cardiac arrest in a cardiac surgical ward setting. Interact Cardiovasc Thorac Surg 2012;15:816-24.

[26] Lin JW, Wang MJ, Yu HY, Wang CH, Chang WT, Jerng JS, et al. Comparing the survival between extracorporeal rescue and conventional resuscitation in adult inhospital cardiac arrests: propensity analysis of three-year data. Resuscitation 2010;81:796-803.

[27] Beuret P, Feihl F, Vogt P, Perret A, Romand JA, Perret C. Cardiac arrest: prognostic factors and outcome at one year. Resuscitation 1993;25:171-9.

[28] Menon PR, Ehlenbach WJ, Ford DW, Stapleton RD. Multiple in-hospital resuscitation efforts in the elderly. Crit Care Med 2014;42:108-17.

[29] Möhnle P, Huge V, Polasek J, Weig I, Atzinger R, Kreimeier U, et al. Survival after cardiac arrest and changing task profile of the cardiac arrest team in a tertiary care center. Sci World J 2012;2012.

[30] Moretti MA, Cesar LAM, Nusbacher A, Kern KB, Timerman S, Ramires JAF.
Advanced cardiac life support training improves long-term survival from in-hospital cardiac arrest. Resuscitation 2007;72:458-65.

[31] O'Sullivan E, Deasy C. In-hospital cardiac arrest at Cork University hospital in 2011. IR Med J 2016;109.

[32] Paniagua D, Lopez-Jimenez F, Londono JC, Mangione CM, Fleischmann K, Lamas GA. Outcome and cost-effectiveness of cardiopulmonary resuscitation after inhospital cardiac arrest in octogenarians. Cardiology 2002;97:6-11.

[33] Rankin APN. The in-hospital Utstein style: use in reporting outcome from cardiac arrest in middlemore hospital 1995-1996. Resuscitation 1998;36:91-4.

[34] Rudiger A, Tobler D, Estlinbaum W. Frequency and outcome of in-hospital resuscitation outside the ICU-setting: a 2 year observational study from Switzerland. Swiss Med Wkly 2004;134:59-62.

[35] Saklayen M, Liss H, Markert R. In-hospital cardiopulmonary resuscitation: survival in 1 hospital and literature review. Medicine (Baltimore) 1995;74:163-75.

[36] Shin TG, Jo IJ, Sim MS, Song YB, Yang JH, Hahn JY, et al. Two-year survival and neurological outcome of in-hospital cardiac arrest patients rescued by extracorporeal cardiopulmonary resuscitation. Int J Cardiol 2013;168:3424-30.

[37] Skrifvars MB, Rosenberg PH, Finne P, Halonen S, Hautamaki R, Kuosa R, et al. Evaluation of the in-hospital Utstein template in cardiopulmonary resuscitation in secondary hospitals. Resuscitation 2003;56:275-82.

[38] Bloom HL, Shukrullah I, Cuellar JR, Lloyd MS, Dudley Jr. SC, Zafari AM. Long-term survival after successful inhospital cardiac arrest resuscitation. AM Hear J 2007;153:831-6.

[39] Skrifvars MB, Saarinen K, Ikola K, Kuisma M. Improved survival after in-hospital cardiac arrest outside critical care areas. Acta Anaesthesiol Scand 2005;49:1534-9.

[40] Stapleton RD, Ehlenbach WJ, Deyo RA, Curtis JR. Long-term outcomes after inhospital CPR in older adults with chronic illness. Chest 2014;146:1214-25.

[41] Tunstall-Pedoe H, Bailey L, Chamberlain DA, Marsden AK, Ward ME, Zideman DA. Survey of 3765 cardiopulmonary resuscitations in British hospitals (the BRESUS study): methods and overall results. BMJ 1992;304:1347.

[42] Vakil K, Kealhofer JV, Alraies MC, Garcia S, McFalls EO, Kelly RF, et al. Long-term outcomes of patients who had cardiac arrest after cardiac operations. Ann Thorac Surg 2016;102:512-7.

[43] Varon J, Walsh GL, Marik PE, Fromm RE. Should a cancer patient be resuscitated following an in-hospital cardiac arrest? Resuscitation 1998;36:165-8.

[44] Wong SPY, Kreuter W, Curtis JR, Hall YN, O'Hare AM. Trends in in-hospital cardiopulmonary resuscitation and survival in adults receiving maintenance dialysis. JAMA Intern Med 2015;175:1028-35.

[45] Yi HJ, Kim YS, Ko Y, Oh SJ, Kim KM, Oh SH. Factors associated with survival and neurological outcome after cardiopulmonary resuscitation of neurosurgical intensive care unit patients. Neurosurgery 2006;59:838-45.

[46] Hessulf F, Herlitz J, Karlsson T, Aune S, Strömsöe A, Källestedt-Södersved ML, et al. Factors of importance to 30-day survival after in hospital cardiac arrest in Sweden A population-based registry study of 15,000 cases. Resuscitation 2015;96:102.

[47] Memar M, Geara S-J, Hjalmarsson P, Allberg A, Bouzereau M, Djärv T. Long-term mortality and morbidity among 30-day survivors after in-hospital cardiac arrests-a Swedish cohort study. Resuscitation 2018;124:76-9.

[48] Thompson LE, Chan PS, Tang F, Nallamothu BK, Girotra S, Daugherty SL, et al. Trends in long-term survival after in-hospital cardiac arrest: insights from get with the guidelines-resuscitation". Circulation 2015;132.

[49] Blumenstein J, Leick J, Liebetrau C, Kempfert J, Gaede L, Gross S, et al. Extracorporeal life support in cardiovascular patients with observed refractory inhospital cardiac arrest is associated with favourable short and long-term outcomes: a propensity-matched analysis. Eur Hear J Acute Cardiovasc Care 2015;5(7):13-22

[50] Chen J, Ou L, Hillman K, Flabouris A, Bellomo R, Hollis SJ, et al. The impact of implementing a rapid response system: a comparison of cardiopulmonary arrests and mortality among four teaching hospitals in Australia. Resuscitation 2014;85:1275-81.

[51] Colmenero Ruiz M, De La Chica Ruiz-Ruano R, Chavero Magro MJ, Perez Villares JM, Reina Toral A, Rodriguez Elvira M. Outcome after cardiorespiratory arrest in a referral hospital reported in Utstein style. Med Intensiva 2004;28:49-56.

[52] Dimopoulou I, Anthi A, Michalis A, Tzelepis GE. Functional status and quality of life in long-term survivors of cardiac arrest after cardiac surgery. Crit Care Med 2001;29:1408-11.

[53] Ezquerra García AM, Suberviola Fernández I, Pavía Pesquera MC. Evaluation of the effectiveness of an in-hospital cardiac alarm system. Enferm Intensiva 2009;20:58-68.

[54] Feingold P, Mina MJ, Burke RM, Hashimoto B, Gregg S, Martin GS, et al. Long-term survival following in-hospital cardiac arrest: a matched cohort study. Resuscitation 2016;99:72-8.

[55] Piscator E, Hedberg P, Göransson K, Djärv T. Survival after in-hospital cardiac arrest is highly associated with the age-combined Charlson co-morbidity Index in a cohort study from a two-site Swedish University hospital. Resuscitation 2016;99:79-83.

[56] WHO. Life expectancy. WHO World Health Organization; 2016.

[57] Bapat V, Allen D, Young C, Roxburgh J, Ibrahim M. Survival and quality of life after cardiac surgery complicated by prolonged intensive care. J Card Surg 2005;20:212-7.

[58] Damuth E, Mitchell JA, Bartock JL, Roberts BW, Trzeciak S. Long-term survival of critically ill patients treated with prolonged mechanical ventilation: a systematic review and meta-analysis. Lancet Respir Med (Elsevier) 2015;3:544-53.

[59] Wong MKY, Morrison LJ, Qiu F, Austin PC, Cheskes S, Dorian P, et al. Trends in short- and long-term survival among out-of-hospital cardiac arrest patients alive at hospital arrival. Circulation 2014;130. 1883-+.

[60] Meaney PA, Nadkarni VM, Kern KB, Indik JH, Halperin HR, Berg RA. Rhythms and outcomes of adult in-hospital cardiac arrest. Crit Care Med 2010;38:101-8.

[61] Lingsma HF. Measuring quality of care: methods and applications to acute 
neurological diseases. Erasmus University Rotterdam; 2010.

[62] Assmann SF, Pocock SJ, Enos LE, Kasten LE. Subgroup analysis and other (mis)uses of baseline data in clinical trials. Lancet 2000;355:1064-9.

[63] Haywood K, Whitehead L, Nadkarni VM, Achana F, Beesems S, Böttiger BW, et al. COSCA (Core outcome set for cardiac arrest) in adults: an advisory statement from the International Liaison Committee on Resuscitation. Resuscitation (Elsevier) 2018;127:147-63.

[64] Perkins GD, Jacobs IG, Nadkarni VM, Berg RA, Bhanji F, Biarent D, et al. Cardiac arrest and cardiopulmonary resuscitation outcome reports: update of the Utstein resuscitation registry templates for out-of-hospital cardiac arrest. Resusc BioMed
Central 2015;96:328-40.

[65] Nolan JP, Soar J, Smith GB, Gwinnutt C, Parrott F, Power S, et al. Incidence and outcome of in-hospital cardiac arrest in the United Kingdom National Cardiac Arrest Audit. Resuscitation 2014;85:987-92.

[66] Regenbogen SE, Dimick JB. Using clinical registries to enhance implementation research. JAMA Surg Am Med Assoc 2018;153:366.

[67] Ahn C, Kim W, Cho Y, Choi K-S, Jang B-H, Lim TH. Efficacy of extracorporeal cardiopulmonary resuscitation compared to conventional cardiopulmonary resuscitation for adult cardiac arrest patients: a systematic review and meta-analysis. Sci Rep Nat (Publishing Group) 2016;6:34208. 